\title{
Personalization of learning situations within a virtual environment for training based on fuzzy clustering
}

\author{
Mohamed Fahim*, Abdeslam Jakimi, Lahcen El bermi \\ Software Engineering and Information Systems, Engineering Team, Computer Sciences Department, Moulay \\ Ismal University, FST Errachidia, Morocco \\ fahim.mohamed89@gmail.com,ajakimi@yahoo.fr, elbermi.lahcen@gmail.com
}

\section{ARTICLE INFO}

Article History:

Received 01 July 2017

Accepted 23 October 2017

Available 26 October 2017

Keywords:

Virtual environments for training

Personalization of learning

Fuzzy clustering

AMS Classification 2010: $68 \mathrm{~T} 05$

\begin{abstract}
Advances in networks, computers and multimedia technology have changed traditional methods for learning and skills training. Nowadays, Virtual Environments for Training (VET) have been popular, they can provide an environment where virtual reality can be used to create interactive interfaces and real-time software that can control every response and action made by the user. VET have proven to be advantageous to put learners into varied training situations to acquire knowledge and competencies, especially when these situations are taking place in uncontrolled circumstances, or when they are dangerous, unrealizable, or expensive to establish in reality. However individual learners find it difficult to select suitable learning situations for their particular situation because often, there is no personalized service to response to the user needs. Personalization of learning in a VET is a very important way of improving the effectiveness and the quality of the training, yet it also a complex process that requires consideration of several factors such as learners profiles. The goal is to associate suitable learning situations to each learner based on his profile. However, personalization of learning becomes an issue with the uncertainty and imprecision of data that may contains a learner profile. To address this issue, this study is an attempt to integrate a fuzzy clustering into the process of the personalization of learning.
\end{abstract}

$(\mathrm{cc}) \mathrm{EY}$

\section{Introduction}

Advances in networks, computers and multimedia technology have changed traditional methods for learning and skills training and have opened up new possibilities for others methods to show up. Nowadays, VET have been popular, they can provide an environment where virtual reality [1] can be used to create interactive interfaces and real-time tools that can monitor every response made by the trainee. A VET can be defined as Computer-Supported Environments for $\mathrm{Hu}-$ man Learning (CSEHL), exploiting virtual reality technologies in order to immerse the learners in a virtual environment enabling them to learn by doing [2]. Training through VET provides significant benefits over other methods. The idea of a VET relies on simulating the actual behavior of a certain process which requires accurate modeling of each part in the process and integration of realtime 3D graphics. In this case, each instrument is electronically driven by real-time computers that generate output signals based on a software model describing the instrument behavior. Learning in open environments like a VET, demands even more personalization approaches to provide learners with individualized learning situations in order to assure the quality of learning. A learning situation contains several features of information necessary to achieve the objective of training,

*Corresponding Author 
such as content description, lecture information, prerequisite information and so on. In a VET, the excellence of learners can be improved by recommending suitable learning situations (personalization), based on each learner's profile. Personalization of learning situations (PLS) relies on the fact that the learning ability of each individual can depend on several factors such as age, gender, duration of training, personal preferences, content of the material. PLS become an issue with the uncertainty and imprecision of data that may contains a learner profile. In this paper an attempt to integrate the fuzzy logic theory and a fuzzy clustering algorithm into the process of the personalization of learning situations is presented. In the following, we first present the related works to the personalization of learning situation (adaptation). Then, we will talk about the fuzzy logic and Fuzzy C-Means (fuzzy clustering algorithm); Then, we present our methodology. Finally, we conclude and reflect on the future of the present work.

\section{Related works}

Each individual's learning ability depend on several factors such as: age or gender. Adapting the learning situations is one of the main interests of current e-learning research in general. The goal is to associate suitable learning situations to each learner based on his/her profile. A profile contains information such as: learner's knowledge level, desired difficulty level. To allow this personalization of learning, many solutions have been proposed. Current methods for personalization of learning can be divided into three groups: (i) oriented activities approaches [3]: where the learning process is represented by a graph in which the activities are identified and decomposed. (ii) Oriented resources approaches ( [4], [5], 6]): in which the learning process returns to select, assemble and present contents, (iii) oriented objectives approaches ( [7], [8]) : in which case the the learning process is seen as a process of satisfaction of pedagogical objectives already defined. These approaches use a set of algorithms and techniques from Artificial Intelligence and Web Semantics known as ant colony optimization ( 9, , 10, [11, [6]), Bayesian networks [7, the algorithm of Support Vector Machines (SVM) [12, ontologies [13]. However, these methods are quite limited in term of handling uncertain and imprecise data. Under the paradigm of fuzzy logic, approaches have been proposed such as learner's profile modeling( [14], [15]), evaluation issue ( [16], [17], 18]), learning styles prediction ( [19], 20]), which cover different sides of e-learning systems.

\section{Fuzzy logic theory}

Human brain can deal with imprecise concepts. For instance, to answer a question about a hotel services, most time answers could be "Not Very Satisfied" or "Quite Satisfied", which are also fuzzy or ambiguous answers. Exactly to what degree is one satisfied or dissatisfied with some hotel services ?These vague answers can only be created and implemented by human beings, but not machines. So, how can computers and machines handle those vague data? Based on this observation, Lotfi A. Zadeh ( [21], [22]) developed fuzzy set theory that generalizes classical set theory to allow the notion of partial membership. This invention was not well recognized until Dr. E. H. Mamdani, who is a professor at London University, applied the fuzzy logic in a practical application to control an automatic steam engine in 1974 [23]. The use of fuzzy logic allows working with quantitative and qualitative descriptions. In fuzzy set theory, an element can belong entirely to a set (degree of belonging is 1), or "almost" belong to it (with a degree of belonging equal to 0.9 for example). Fuzzy logic has been successfully employed in a variety of applications in recent years( [24, [25], [26]).

\section{Fuzzy C-means}

The Fuzzy C-Means (FCM) algorithm is a clustering algorithm proposed by Bezdek [27. It is useful when the required number of clusters is predetermined; thus, the algorithm tries to put each of the data points to one of the clusters. In each iteration of the FCM algorithm, the following objective function $\mathrm{J}$ is minimized:

$$
J=\sum_{i=1}^{N} \sum_{j=1}^{C} \mu_{i j}\left\|x_{i}-c_{j}\right\|^{2}
$$

- $N$ is the number of data points.

- $C$ is the number of clusters required.

- $c_{j}$ is the centre vector for cluster.

- $\mu_{i j}$ is the degree of membership for the $i$ th data point $x_{i}$ in cluster $j$

- The norm, $\left\|x_{i}-c_{j}\right\|$ measures the similarity (or closeness) of the data point $x_{i}$ to the centre vector $c_{j}$ of cluster $j$.

For a given data point $x_{i}$, the degree of its membership to cluster $\mathrm{j}$ is calculated as follows:

$$
\mu_{i j}=\frac{1}{\sum_{k=1}^{C}\left(\frac{\left\|x_{i}-c_{j}\right\|}{\left\|x_{i}-c_{k}\right\|}\right)^{\frac{2}{m-1}}}
$$


where, $\mathrm{m}$ is the fuzziness coefficient and the centre vector $c_{j}$ is calcuated as follows:

$$
C_{j}=\frac{\sum_{i=1}^{N} \mu_{i j}^{m} * x_{i}}{\sum_{i=1}^{N} \mu_{i j}^{m}}
$$

In equation (3):

- $\mu_{i j}$ is the value of the degree of membership calculated in the previous iteration(equation 2)

- At the start of the algorithm, the degree of membership for data point $i$ to cluster $j$ is initialised with a random value . $\theta_{i j}, 0 \leq \theta_{i j} \leq 1$, such that $\sum_{J}^{C} \mu_{i j}=1$

- In equations (2) and (3) the fuzziness coefficient $\mathrm{m}$, where $1<m<\infty$ :measures the tolerance of the required clustering. This value determines how much the clusters can overlap with one another: The higher the value of $\mathrm{m}$, the larger the overlap between clusters.

Termination condition :

- The required accuracy of the degree of membership determines the number of iterations completed by the FCM algorithm.

$$
\epsilon=\Delta_{i}^{N} \Delta_{j}^{C}\left|\mu_{i j}^{k+1}-\mu_{i j}^{k}\right|
$$

where, $\mu_{i j}^{k}$ and $\mu_{i j}^{k+1}$ are respectively the degree of membership at iteration $\mathrm{k}$ and $\mathrm{k}+1$, and the operator $\Delta$, when supplied a vector of values, returns the largest value in that vector.

\section{Proposal}

The architecture of the system we are developing is shown in the figure 1 . The first step in the operation of our system is to collect users data to build a learner profile. Information which forms a learning profile are the following:

- Learning session duration

- Gender

- Level of difficulty

- Desired language

- Current knowledge level

- Age

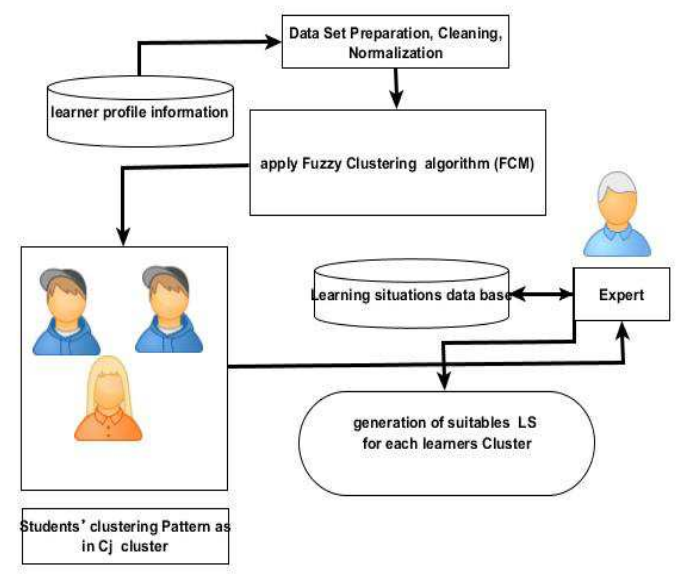

Figure 1. Overview of our approach.

The second step is the data set preparation, it involves for example a domain, transformation where crisp inputs are transformed into fuzzy inputs. (for instance : a learning situation duration $=60 \mathrm{~min} \Rightarrow$ learning situation duration is Medium). Afterwards, the FCM is adopted for classification of feature (learners) selection into $c_{j}$ classes based on values of each students profile attributes. Finally the expert who knows very well the activity which has to be undertaken by the learner, associate for each class of learners suitable learning situations.

Table 1. Extract of learners dataset

\begin{tabular}{ccccc}
\hline Learners & Score & Age & Duration(min) & Difficulty \\
\hline lear1 & 11 & 23 & 80 & 1 \\
lear2 & 3.5 & 22 & 60 & 2 \\
lear3 & 12 & 20 & 70 & 1 \\
lear4 & 18.5 & 22 & 60 & 3 \\
lear5 & 5 & 25 & 70 & 1 \\
lear6 & 18 & 21 & 75 & 1 \\
lear7 & 6 & 27 & 70 & 1 \\
lear8 & 5.75 & 21 & 65 & 1 \\
lear9 & 4 & 25 & 70 & 1 \\
lear10 & 10 & 21 & 85 & 1 \\
\hline
\end{tabular}

The prototype of our model was tested using twenty learners. The table 1 shows an extract of those learners and information that constitutes their profiles. We did not integrate the "language" and the "gender" information in the dataset, they will be taken in consideration later, during the execution on the platform. The FCM clustering algorithm was run on the dataset and iterated to converge and terminate at $\epsilon=0.00001$. The pretermied number of cluster was $C=3$. In this work, the larger is the number of clusters, the higher is the personalization of learning. The output of the algorithm is shown in figure 2, which shows each leaner and the cluster to which he belongs. Each learner has varied degree of 
membership value of belonging to each of the three dimensions (Clusters) and the highest value was inferred as the likely strong class the learner should belong. Table 2 shows degree of membership of each learner to each cluster.

Table 2. Degree of membership

\begin{tabular}{cccc}
\hline Learners & 1st Cluster & 2nd Cluster & 3rd Cluster \\
\hline lear1 & 0.046269342 & 0.105947344 & 0.84778331 \\
lear2 & 0.254602401 & 0.470097456 & 0.27530014 \\
lear3 & 0.258032639 & 0.180264197 & 0.56170316 \\
lear4 & 0.762457186 & 0.115903344 & 0.12163947 \\
lear5 & 0.005913503 & 0.978024006 & 0.01606249 \\
lear6 & 0.904823898 & 0.033261791 & 0.06191431 \\
lear7 & 0.068760067 & 0.797379013 & 0.13386092 \\
lear8 & 0.186612866 & 0.395596766 & 0.41779037 \\
lear9 & 0.012906196 & 0.952466943 & 0.03462686 \\
lear10 & 0.080884083 & 0.091845524 & 0.82727039 \\
\hline
\end{tabular}

The efficiency of this approach is obtained considering the output of which the algorithm is able to identify individual learners into various clusters each belongs to with the varied degree of membership values.

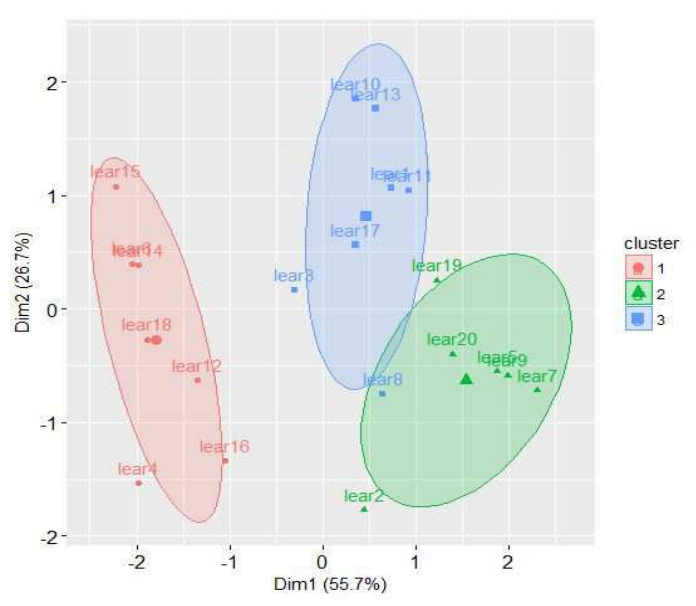

Figure 2. Clustering result with FCM.

\section{Conclusion}

This paper has outlined the development of a fuzzy based approach for the generation of learning situations within a virtual environment for training. The main advantage of this proposed methodology is that it is efficient in handling the uncertainty in the learners profile. The FCM is used to make clusters of similar learners in order to generate, suitable learning situations for each leaner or group of learners. However, a number of further data, in particular, learners feedback information is required to promote the functionality of the system. The ongoing work aims at including this proposed approach in our previous work [28], in order to generate adaptable and effective pedagogical scenarios for VET.

\section{Acknowledgments}

I must acknowledge the assistance and scholarly guidance of my supervisors who also happens to be co-authors of this paper.

\section{References}

[1] Fuchs, P., \& Moreau, G. (2006). Le trait de la ralit virtuelle. Les Presses de lEcole des Mines de Paris, Paris.

[2] Marion, N. (2010). Modlisation de scnarios pdagogiques pour les environnements de ralit virtuelle dapprentissage humain, Phd thesis, universit de Bretagne Occidentale.

[3] Naji, A., \& Ramdani, M. (2013). Using the ant colony algorithm to establish the best path of learning activities. Applied Mathematical Sciences, 7(78), 38733881.

[4] Karampiperis, P., \& Sampson, D. (2005). Automatic learning object selection and sequencing in web-based intelligent learning systems. In: Zongmin Ma, Ed. Web-Based Intelligent e-Learning Systems: Technologies and Applications, Information Science Publishing, 56-71.

[5] De-Marcos, L., Martinez, J.-J., \& Gutierrez, J.-A. (2008). Swarm intelligence in e-learning: A learning object sequencing agent based on competencies. In : Proc. The 10th annual conference on Genetic and evolutionary computation. 17-24.

[6] Valigiani. G., Lutton. E., Fonlupt, C., \& Collet, P. (2007). Optimisation par hommilire de chemins pdagogiques pour un logiciel d'e-learning. RSTI TSI, 26(10), 1245-1268.

[7] Bouhdidi, J. E., Ghailani, M., \& Fennan, A. (2013). An intelligent architecture for generating evolutionary personalized learning paths based on learner profiles. Journal of Theoretical and Applied Information Technology (JATIT). 57(2), 294-304.

[8] Talhi, S., Djoudi, M., Ouadfel, S., \& Zidat, S. (2007). Un canevas de tuteur intelligent hypermdia pour lapprentissage distance universitaire. In : Proc. 4th International Conference on Computer Integrated Manufacturing.

[9] Kardan, A. A., Ebrahim, M. A., \& Imani, M. B. (2014). A new personalized learning path generation method: Acomap. Indian Journal Science Research. $5(1), 17-24$.

[10] Kumar, A,. Nalavade, J., Yeola, V.,Vivek, V., \& Y. Srivastava. (2013). An adaptive learning system based on ant colony algorithm. International Journal of Soft Computing and Engineering (IJSCE). 3(2), 212-214.

[11] Pushpa, M. (2012). Aco in e-learning: Towards an adaptive learning path. International Journal on Computer Science and Engineering (IJCSE), 4(3), 458-462.

[12] Ouraiba, E.-A., Chikh, A., Taleb-Ahmed A., \& Yeb dri, Z. E. (2009). Automatic personalization of learning scenarios using svm. In : Proc. International Conference of Advanced Learning Technologies, 183-185.

[13] Ghailani, M., Bouhdidi, J. E., \& Fennan, A. (2014). Towards an adaptive e-learning solution based on ontologies and competencies approach. International Journal of Computer Applications, 98(21), 42-52. 
[14] Chrysafiadi, K., \& Virvou, M. (2012). Evaluating the integration of fuzzy logic into the student model of a web-based learning environment. Expert Systems with Applications, 39(18), 13127-13134.

[15] Al-Aubidy, Kasim M. (2005). Applying Fuzzy Logic for Learner Modeling and Decision Support in Online Learning Systems. Journal of Educational Technology, 2(3), 76-85.

[16] Khan, F. A., Shahzad, F., \& Altaf, M. (2017). Fuzzy based approach for adaptivity evaluation of web based open source Learning Management Systems. Cluster Computing, 1-11.

[17] Samarakou, M., Papadakis, A., Prentakis, P., Karolidis, D., \& Athineos, S. (2009). A Fuzzy Model for Enhanced Student Evaluation. International Journal of Learning, 16(10). 103-118.

[18] Omidiora, E. O., Olabiyisi, S. O. Okediran, O. O., \& Isiaka, R. M. (2013). Learner Activities Evaluation Model: A Neuro-Fuzzy Approach. International Journal of e-Education, e-Business, e-Management and eLearning (IJEEEE). 3(5), 421-424.

[19] Crockett, K., Latham, A., \& Whitton, N. (2017). On predicting learning styles in conversational intelligent tutoring systems using fuzzy decision trees. International Journal of Human-Computer Studies, 97, 98115.

[20] Deborah, J., Sathiyaseelan, R., Audithan, S., \& Vijayakumar, P. (2015). Fuzzy-logic based learning style prediction in e-learning using web interface information. Electrical and Computer Sciences, 40(2), 379394.

[21] Zadeh, L. A. (1965). Fuzzy set , Information and Control.338-353.

[22] Zadeh, L. A. (1975). The concept of a linguistic variable and its application to approximate reasoning, Information Sciences, 199-49.

[23] Mamdani E. H., \& Assilion, S. (1974). An Experiment in Linguistic Synthesis With a Fuzzy Logic Controller, Intl J. ManMachine Stud. 7, 1-13.
[24] Lin, C. T., Fan, K. W., Yeh, C. M., Pu, H. C., \& Wu, F.Y. (2006). High-accuracy skew estimation of document images, International Journal of Fuzzy Systems, 8(3), 119-126.

[25] LinLin C. T., \& Chin, C. L. (2006). Using fuzzy inference and cubic curve to detect and compensate backlight image, International Journal of Fuzzy Systems, 8(1), 2-13.

[26] Wallace, M., Ioannou, S., Karpouzis, K., \& Kollias, S. (2006). Possibilistic rule evaluation: A case study in facial expressionanalysis, International Journal of Fuzzy Systems. 8(4),219-223.

[27] Bezdek, J. C.(1981). Pattern recognition with fuzzy objective function. New York: Plenum. Kluwer Academic Publishers Norwell, MA, USA.

[28] Fahim, M., Jakimi, A., \& El bermi, L.(2016). Pedagogical Scenarization for Virtual Environments for Training: Towards Genericity, Coherence and Adaptivity. International Journal of Advanced Engineering Research and Science (IJAERS), 12(3), 96-103.

Mohamed Fahim received the Master degree in Intelligent Systems and Networks in 2013 from Faculty of Science and Technology of Fes, Morocco. Currently, he is a PhD Student in Computer Science. He is also member of Software Engineering \& Information Systems Engineering Team. His research interests include pedagogical scenarization and virtual environments for training (VET).

Abdeslam Jakimi is a teacher at the faculty of science and technology of Errachidia. His research interests include software engineering and e-learning.

Lahcen El Bermi is a teacher at the faculty of science and technology of Errachidia. His research interests include software engineering and e-learning.

An International Journal of Optimization and Control: Theories \& Applications (http://ijocta.balikesir.edu.tr)

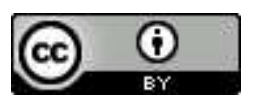

This work is licensed under a Creative Commons Attribution 4.0 International License. The authors retain ownership of the copyright for their article, but they allow anyone to download, reuse, reprint, modify, distribute, and/or copy articles in IJOCTA, so long as the original authors and source are credited. To see the complete license contents, please visit http://creativecommons.org/licenses/by/4.0/. 